\title{
Socioeconomic Factors Associated with Underweight and Stunting among Adolescents of Jimma Zone, South West Ethiopia: A Cross-Sectional Study
}

\author{
Huruy Assefa, ${ }^{1}$ Tefera Belachew, ${ }^{2}$ and Legesse Negash $^{3}$ \\ ${ }^{1}$ Department of Public Health, College of Health Sciences, Mekelle University, P.O.Box 1871, Mekelle, Ethiopia \\ ${ }^{2}$ Department of Population and Family Health, College of Public Health and Medical Sciences, Jimma University, \\ P.O.Box 1104, Jimma, Ethiopia \\ ${ }^{3}$ Department of Statistics, College of Natural Sciences, Jimma University, P.O.Box 1104, Jimma, Ethiopia
}

Correspondence should be addressed to Huruy Assefa; huruyame@yahoo.com

Received 16 September 2013; Accepted 24 October 2013

Academic Editors: K. McLeroy and A. Rosano

Copyright $\odot 2013$ Huruy Assefa et al. This is an open access article distributed under the Creative Commons Attribution License, which permits unrestricted use, distribution, and reproduction in any medium, provided the original work is properly cited.

\begin{abstract}
Background. Nutrition during adolescence plays an important role in the individual's life. Socioeconomic status, age, sex, and mothers' educational level are among the important determinant factors of nutritional status of adolescents. In this study, we test the competing hypotheses about the correlates of nutritional status among Ethiopian adolescents. Methods. We report a total of 2084 adolescents and univariate and multivariable linear regression were used to assess socioeconomic factors associated with underweight and stunting among adolescents. Results. Age, highest grade completed, job, and last attended in community school were positively associated with BMI for Age $z$-score and highest grade completed, household income, and job were positively associated with Height for Age $z$-score. However, male gender was negatively associated with BMI for Age $z$-score and male gender, last attended in community school, abdominal pain, and household size were negatively associated with Height for Age $z$-score. Conclusion. Age of the adolescents, gender, educational status, employment status, and type of last school attended are associated with underweight; gender, place of residence, household size, household income, educational status, employment status, type of last school attended, and abdominal pain are associated with stunting. The findings reflect socio-economic characteristics are associated with underweight and stunting.
\end{abstract}

\section{Background of the study}

The world population is believed to have reached over 6.6 billion [1]. Adolescence is a particularly unique period in life because it is a time of intense physical, psychosocial, and cognitive development. Nutrition during adolescence plays an important role in the individual's life. Increased nutritional needs to adolescents gain up to $50 \%$ of their adult weight, more than $20 \%$ of their adult height, and $50 \%$ of their adult skeletal mass [2].

There are different factors that affect nutritional status of adolescents. Socioeconomic status, age, sex, and mothers' educational level are among the important determinant factors of nutritional status of adolescents [3-6]. Studies have shown that adolescent women from low economic status households were most affected by malnutrition and the higher the level of education, the lower the proportion of undernourished adolescent women, and rural adolescent women are more likely to suffer from chronic energy deficiency than adolescent women in urban areas. [7, 8].

There are only a handful of studies on adolescent malnutrition in developing countries-they indicate that younger adolescents tend to be more undernourished than older adolescents, and, contrary to expectations, boys are almost twice as undernourished as girls. In addition, these few studies suggest that there are more undernourished adolescents in Sub-Saharan Africa and a higher prevalence in rural than in urban areas [9].

In Ethiopia, undernourishment among preschool-aged children has been well documented [10], but factors affecting 
the nutritional status of adolescents have not been studied in detail [11]. The available studies focused on factors affecting pregnancy outcomes rather than on problems associated with normal growth and development of adolescents [12, 13]. A recent study on the nutritional status of adolescent girls from rural communities of Tigray, Northern Ethiopia [5], has helped to close the research gap in the area, although it is still focused only on rural adolescent girls, on small geographic area and small population. This study is expected to play important role in identifying the socio-economic factors associated with underweight and stunting among adolescents of Jimma zone, south west Ethiopia. In this study, we test the competing hypothesis about the socio-economic factors associated with underweight and stunting among Ethiopian adolescents.

\section{Methods}

2.1. Study Sample. A community-based cross-sectional study was conducted from 2010 adolescents enrolled in the second round of the five-year longitudinal study of adolescents in Jimma zone, South west Ethiopia. A census was done to generate the list of all households which gave a sampling frame for random selection of 3,700 households from the total of 5,795 households in the list. A two-stage sampling plan was used to select the target sample of adolescents. Households were classified into urban (Jimma city), semiurban (Serbo, Dedo, and Yebbu towns), and six rural communities in the vicinity of the small towns. At the first stage, households were randomly sampled with the sample size in each kebele determined by the relative proportion of the study population in the kebele and the overall target sample size. In the second stage, one adolescent (a boy or a girl) was randomly selected from each household using a Kish Table [14]. Using this sampling strategy, a total of 1059 boys and 1025 girls were interviewed in round one. This paper reports on all the 2084 adolescents in the second round of the five-year longitudinal family survey of youth.

2.2. Measurements. Structured adolescent level questionnaires were used to collect data. The questionnaires were interviewer-administered and translated into Amharic and Oromifa languages and checked for consistency by another person who speaks both Oromifa and English. The questionnaire focused on issues related to adolescents' experiences of nutritional status, socio-economic, health, food insecurity, and anthropometric measurements of the adolescent. The interview was conducted in a private place by an interviewer of the same sex.

The interviewers received one week of intensive training prior to the pretest and an additional week of training was given with the final version of the questionnaire before the start of the actual interviews. Supervisors checked the data collection process and filled questionnaires daily to ensure accuracy of the data. The research team supervised the data collection team every week through meetings and checking of the filled questionnaires.
We measured height to the nearest $0.1 \mathrm{~cm}$ using a stadiometer (SECA, Hannover, Germany) and weight to the nearest $0.1 \mathrm{~kg}$ using digital scales (SECA). The level of stunting (height for age $z$-scores), which is an indicator of chronic malnutrition, and wasting (weight for age $z$-scores), which is another indicator of malnutrition, were calculated using WHO Athro-Plus software [15]. Thus, those below -2 standard deviations of the NCHS median reference for height-for-age and weight-for-height were defined as stunting and wasting, respectively.

Socio-economic variables like age, sex, place of residence, marital status, whether the adolescents have a child, highest grade completed, type of school completed, religion, whether the adolescents have a job, household income, household size, mother's education status and father's education status, health related variables like fever, cough, fast breathing, diarrhea, vomiting, unable to drink or eat, ulcer, Depression, sleep under insecticide-treated mosquito bed net, currently smoke tobacco, does any member of the household smoke, and food security variables were recorded. The questionnaire was tested on 200 adolescents (not included in the sample) selected from a community in Jimma city.

2.3. Data Analysis. The data were double-entered, checked for missing values and outliers using SPSS (SPSS Inc. version 16.1, Chicago, Illinois), and analyzed using SAS version 9.2. First, univariate linear regression analyses were conducted. To identify the predictors of underweight (BMI for Age $z$ score) and stunting (Height for Age $z$-score), multivariable linear regression analysis with stepwise variable selection and AIC criteria procedure was employed and variables that showed statistically significant $(P<0.05)$ in the univariate analyses were entered to the multivariable linear regression.

Goodness-of-fit of the models was assessed using Akaike's information criterion (AIC) and adjusted- $\mathrm{R}^{2}$ and partial regression residual plots showed that all had linear relationship. Normality of the data was assessed using a Q-Q plot and there was no need for transformation; outliers and influential observations were not as such influential and then retained in the final model. Colinearity between predictor variables was checked using variance inflation factor (VIF); interaction and confounding variables were checked. All tests were twosided and a $P<0.05$ was considered statistically significant. We present the results of the linear regression as parameter estimates $(\beta), P$ values, and $95 \%$ confidence intervals.

2.4. Ethical Consideration. Informed verbal consent was obtained both from the parents and each adolescent before the interview or measurement. The study obtained ethical clearance from the Ethical Review Board of Jimma University (Ethiopia). The head of the household was interviewed by using the household questionnaire.

We did not obtain written verbal consent, because most of the respondents did not write and read well. We first read the consent paper and explain the objective of the study in front of each respondent and after they agree on the objective of the study, they sign. The ethics committees also approved the consent procedure after we explain the procedures. 
TABLE 1: Sociodemographic characteristics of nutritional status of adolescents, Jimma zone, south west Ethiopia, 2011.

\begin{tabular}{|c|c|c|c|c|c|c|c|}
\hline \multirow[b]{2}{*}{ Variables } & \multirow[b]{2}{*}{ Category } & \multicolumn{3}{|c|}{ Prevalence (\%) } & \multicolumn{3}{|c|}{ Prevalence (\%) } \\
\hline & & $\begin{array}{l}\text { Underweight } \\
(\mathrm{HAZ}<-2)\end{array}$ & Total & $P$ value & $\begin{array}{c}\text { Stunting } \\
(\mathrm{HAZ}<-2)\end{array}$ & $\begin{array}{l}\text { Total number of } \\
\text { adolescents }\end{array}$ & $P$ value \\
\hline \multirow{3}{*}{ Place of residence } & Urban & $620(83)$ & 743 & \multirow{3}{*}{$P<0.001$} & $88(12)$ & 743 & \multirow{3}{*}{$P<0.001$} \\
\hline & Semiurban & $459(84)$ & 545 & & $90(16)$ & 546 & \\
\hline & Rural & $498(75)$ & 663 & & $135(20)$ & 667 & \\
\hline \multirow{2}{*}{ Marital status } & Single & $1571(81)$ & 1945 & \multirow{2}{*}{0.232} & $313(16)$ & 1950 & \multirow{2}{*}{0.284} \\
\hline & Married & $6(100)$ & 6 & & $0(0)$ & 6 & \\
\hline \multirow{2}{*}{ Sex } & Female & $839(89)$ & 941 & \multirow{2}{*}{$P<0.001$} & $103(11)$ & 942 & \multirow{2}{*}{$P<0.001$} \\
\hline & Male & $738(73)$ & 1010 & & $210(21)$ & 1014 & \\
\hline \multirow{2}{*}{ Ever had child } & No & $1568(81)$ & 1941 & \multirow{2}{*}{0.460} & $312(16)$ & 1945 & \multirow{2}{*}{0.794} \\
\hline & Yes & $9(90)$ & 10 & & $1(9)$ & 11 & \\
\hline \multirow{4}{*}{$\begin{array}{l}\text { Type of last school } \\
\text { attended }\end{array}$} & Government & $1511(81)$ & 1866 & \multirow{4}{*}{0.680} & $291(16)$ & 1870 & \multirow{4}{*}{0.003} \\
\hline & Private & $16(94)$ & 17 & & $4(24)$ & 17 & \\
\hline & Community & $4(100)$ & 4 & & $0(0)$ & 4 & \\
\hline & Other & $46(72)$ & 64 & & $18(28)$ & 65 & \\
\hline \multirow{4}{*}{ Religion } & Muslim & $918(79)$ & 1165 & \multirow{4}{*}{0.008} & $191(16)$ & 1170 & \multirow{4}{*}{0.681} \\
\hline & Orthodox & $562(85)$ & 664 & & $104(16)$ & 664 & \\
\hline & Protestant & $91(81)$ & 113 & & $16(14)$ & 113 & \\
\hline & Other & $6(67)$ & 9 & & $2(22)$ & 9 & \\
\hline \multirow{2}{*}{ Job } & No & $1117(80)$ & 1398 & \multirow{2}{*}{0.097} & $234(17)$ & 1399 & \multirow{2}{*}{0.166} \\
\hline & Yes & $460(83)$ & 553 & & $79(14)$ & 557 & \\
\hline \multirow{3}{*}{ Fathers' education } & No education & $487(80)$ & 611 & \multirow{3}{*}{0.086} & $188(17)$ & 1089 & \multirow{3}{*}{0.018} \\
\hline & Primary & $633(79)$ & 800 & & $102(16)$ & 624 & \\
\hline & Secondary & $371(84)$ & 441 & & $19(9)$ & 213 & \\
\hline \multirow{3}{*}{ Mothers' education } & No education & $860(79)$ & 1086 & \multirow{3}{*}{0.127} & $112(18)$ & 614 & \\
\hline & Primary & $513(82)$ & 623 & & 137 (17) & 801 & 0.010 \\
\hline & Secondary & $178(84)$ & 212 & & $53(12)$ & 441 & \\
\hline Age in years & $( \pm \mathrm{SD})$ & $14.78( \pm 1.34)$ & 2083 & 0.001 & $14.78( \pm 1.34)$ & 2083 & $P<0.001$ \\
\hline Highest grade com & pleted $( \pm S D)$ & $5.16( \pm 2.66)$ & 2084 & $P<0.001$ & $5.16( \pm 2.66)$ & 2084 & $P<0.001$ \\
\hline Household incor & me $( \pm S D)$ & $105.77( \pm 188.13)$ & 2084 & 0.686 & $\begin{array}{c}105.77 \\
( \pm 188.13)\end{array}$ & 2084 & 0.539 \\
\hline Household siz & $( \pm S D)$ & $8.49( \pm 3.42)$ & 2084 & 0.021 & $8.49( \pm 3.42)$ & 2084 & 0.166 \\
\hline
\end{tabular}

\section{Results}

Of 2084 adolescents included in the study (Table 1), 1951 and 1956 adolescents' complete data were available for BMI for Age $z$-score and Height for Age $z$-score. Out of 1951 and 1956 adolescents covered in the study for BMI for Age $z$-score and Height for Age $z$-score, 1577 (80.83\%) and 313 (16\%) were found to be underweight and stunted, respectively.

Most of the underweight adolescents (Table 1) were females $(53.20 \%)$, reside in urban $(39.32 \%)$, single $(99.68 \%)$, muslim by religion $(58.21 \%)$, no child $(99.43 \%)$, attended last school in government $(95.82 \%)$, no job $(70.83 \%)$, adolescent father's education had primary $(42.45 \%)$, and adolescent mother's education had no education (55.45\%).

And most of the stunted adolescents (Table 1) were males $(67 \%)$, reside in rural $(43 \%)$, single $(100 \%)$, muslim by religion $(61 \%)$, no child $(99.68 \%)$, attended last school in government (93\%), no job (75\%), adolescent father's education had no education (61\%), and adolescent mother's education had primary (45\%).

The mean $( \pm$ SD) age of the adolescents was $14.78( \pm 1.34)$ and the mean $( \pm \mathrm{SD})$ highest grade completed, household income, and household size of the adolescents were 5.16 $( \pm 2.66), 105.77( \pm 188.13)$, and $8.49( \pm 3.42)$, respectively, for both underweight and stunted adolescents.

Of the underweight adolescents (Table 2), fever (86\%), cough (43\%), vomiting (35\%), unable to eat or drink (49\%), and abdominal pain (31\%) were the health problems in the study area. And of the 313 stunted adolescents, fever (85\%), cough (49\%), vomiting (35\%), unable to eat or drink (45\%), and abdominal pain (39\%) were the health problems. Only $21 \%$ of the underweight and stunted adolescents did not secure their food in the study area. 
TABLE 2: Health related and food insecurity characteristics of nutritional status of adolescents, Jimma zone, south west Ethiopia, 2011.

\begin{tabular}{|c|c|c|c|c|c|c|c|}
\hline \multirow[b]{2}{*}{ Variables } & \multirow[b]{2}{*}{ Category } & \multicolumn{3}{|c|}{ Prevalence (\%) } & \multicolumn{3}{|c|}{ Prevalence (\%) } \\
\hline & & $\begin{array}{l}\text { Underweight } \\
(\mathrm{HAZ}<-2)\end{array}$ & Total & $P$ value & $\begin{array}{c}\text { Stunting } \\
(\mathrm{HAZ}<-2)\end{array}$ & Total & $P$ value \\
\hline \multirow{2}{*}{ Diarrhea } & No & $1372(87)$ & 1696 & \multirow{2}{*}{0.849} & $269(86)$ & 1701 & \multirow{2}{*}{0.558} \\
\hline & Yes & $205(13)$ & 255 & & $44(14)$ & 255 & \\
\hline \multirow{2}{*}{ Fever } & No & $228(14)$ & 284 & \multirow{2}{*}{0.799} & $48(15)$ & 286 & \multirow{2}{*}{0.697} \\
\hline & Yes & $1349(86)$ & 1667 & & $265(85)$ & 1670 & \\
\hline \multirow{2}{*}{ Cough } & No & $903(57)$ & 1101 & \multirow{2}{*}{0.130} & $161(51)$ & 1105 & \multirow{2}{*}{0.049} \\
\hline & Yes & $674(43)$ & 850 & & $152(49)$ & 851 & \\
\hline \multirow{2}{*}{ Fast breathing } & No & $1191(76)$ & 1454 & \multirow{2}{*}{0.038} & $239(76)$ & 1459 & \multirow{2}{*}{0.433} \\
\hline & Yes & $386(24)$ & 497 & & $74(24)$ & 497 & \\
\hline \multirow{2}{*}{ Vomiting } & No & $1022(65)$ & 1259 & \multirow{2}{*}{0.601} & $204(65)$ & 1264 & \multirow{2}{*}{0.823} \\
\hline & Yes & $555(35)$ & 692 & & $109(35)$ & 692 & \\
\hline \multirow{2}{*}{ Could not eat or drink } & No & $804(51)$ & 965 & \multirow{2}{*}{0.006} & $159(51)$ & 970 & \multirow{2}{*}{0.641} \\
\hline & Yes & $773(49)$ & 986 & & $154(49)$ & 986 & \\
\hline \multirow{2}{*}{ Abdominal pain } & No & $1086(69)$ & 1327 & \multirow{2}{*}{0.099} & $192(61)$ & 1332 & \multirow{2}{*}{0.005} \\
\hline & Yes & $491(31)$ & 624 & & $121(39)$ & 624 & \\
\hline \multirow{2}{*}{ Genital discharge or ulcer } & No & $1562(99)$ & 1931 & \multirow{2}{*}{0.506} & $310(99)$ & 1936 & \multirow{2}{*}{0.902} \\
\hline & Yes & $15(1)$ & 20 & & $3(1)$ & 20 & \\
\hline \multirow{2}{*}{$\begin{array}{l}\text { Depression/extreme } \\
\text { sadness/worry }\end{array}$} & No & $1232(78)$ & 1529 & \multirow{2}{*}{0.586} & $242(77)$ & 1534 & \multirow{2}{*}{0.603} \\
\hline & Yes & $345(22)$ & 422 & & $71(23)$ & 422 & \\
\hline Sleeps under insecticide & No & $1376(87)$ & 1709 & 0.347 & $282(90)$ & 1714 & 0.148 \\
\hline & Yes & $201(13)$ & 242 & & $31(10)$ & 242 & \\
\hline & No & $1571(99.62)$ & 1941 & 0.093 & $311(99)$ & 1946 & 0.730 \\
\hline Smoking & Yes & $6(0.38)$ & 10 & 0.093 & $2(1)$ & 10 & 0.130 \\
\hline Anyone in household & No & $1377(87)$ & 1707 & 0.630 & $276(88)$ & 1712 & 0.703 \\
\hline smokes tobacco products & Yes & $200(13)$ & 244 & 0.630 & $37(12)$ & 244 & 0.703 \\
\hline Adolescent food & Secure & $1247(79)$ & 1549 & 0.472 & $247(79)$ & 1554 & 0.799 \\
\hline insecurity & Nonsecure & $330(21)$ & 402 & $0.4 / 2$ & $66(21)$ & 402 & 0.199 \\
\hline
\end{tabular}

In bivariate linear regression models (Table 3), residence in semirural, age, highest grade completed, last attended in community school, household income, adolescent mothers with secondary education, and adolescent fathers with secondary education were positively associated with BMI for Age $z$-score, while residence in rural, male gender, and Household size were negatively associated with BMI for Age $z$-score.

After adjusting for all other variables in the multivariable linear regression model (Table 3), age, highest grade completed, job, and last attended in community school were positively associated with BMI for Age $z$-score. However, male gender was negatively associated with BMI for Age $z$ score. The effect of residence in semiurban, residence in rural, household income, household size, adolescent mothers with secondary education, and adolescent fathers with secondary education disappeared in the multivariable linear regression model.

3.1. Determinants of Nutrition Status of Adolescents in terms of Height for Age z-Scores. In bivariate linear regression models (Table 4), age, highest grade completed, household income, job, and adolescent fathers with secondary education were positively associated with BMI for Age $z$-score, while residence in rural, male gender, last school attended in community school, abdominal pain, and household size were negatively associated with the Height for Age $z$-score.

After adjusting for all other variables in the multivariable linear regression model (Table 4), highest grade completed, household income, and job were positively associated with Height for Age $z$-score, while male gender, last attended in community school, abdominal pain, and household size were negatively associated with Height for Age $z$-score. The effect of adolescents' residence in rural, age of the adolescent, adolescent mothers with secondary education, and adolescents fathers with secondary education disappeared in the multivariable linear regression model.

\section{Discussion}

Our results showed that age was positively associated with BMI for Age $z$-score. An association of age with BMI for 
TABLE 3: Predictors of BMI for age Z-scores in adolescents in Jimma zone, south west Ethiopia, 2011.

\begin{tabular}{|c|c|c|c|c|c|c|c|c|}
\hline \multirow{3}{*}{$\begin{array}{l}\text { Variables } \\
\text { Residence in semiurban }\end{array}$} & \multicolumn{4}{|c|}{ Univariate linear regression } & \multicolumn{4}{|c|}{ Multivariable linear regression } \\
\hline & \multirow{2}{*}{$\frac{\beta}{0.1283}$} & \multicolumn{2}{|c|}{$95 \% \mathrm{CI}$} & \multirow{2}{*}{$\frac{P \text { value }}{0.0301}$} & \multirow{2}{*}{$\frac{\beta}{0.0820}$} & \multicolumn{2}{|c|}{$95 \% \mathrm{CI}$} & \multirow{2}{*}{$\begin{array}{c}P \text { value } \\
0.2204\end{array}$} \\
\hline & & 0.0124 & 0.2443 & & & -0.0492 & 0.2132 & \\
\hline Residence in rural & -0.3132 & -0.4223 & -0.2041 & 0.0000 & -0.0990 & -0.2628 & 0.0649 & 0.2363 \\
\hline Sex & -0.7330 & -0.8321 & -0.6340 & 0.0000 & -0.7419 & -0.8434 & -0.6404 & 0.0000 \\
\hline Age in years & 0.1131 & 0.0746 & 0.1517 & 0.0000 & 0.0594 & 0.0173 & 0.1015 & 0.0057 \\
\hline Highest grade completed & 0.0685 & 0.0489 & 0.0881 & 0.0000 & 0.0554 & 0.0290 & 0.0817 & 0.0000 \\
\hline Private school & 0.0278 & -0.4102 & 0.4658 & 0.9009 & 0.1677 & -0.2662 & 0.6016 & 0.4485 \\
\hline Community school & 0.7070 & 0.0119 & 1.4020 & 0.0462 & 0.7912 & 0.0238 & 1.5585 & 0.0433 \\
\hline Other type of school & -0.4743 & -1.0516 & 0.1029 & 0.1072 & 0.2767 & -0.2914 & 0.8447 & 0.3396 \\
\hline Household income & 0.0004 & 0.0001 & 0.0006 & 0.0072 & 0.0001 & -0.0002 & 0.0004 & 0.6156 \\
\hline Job & 0.1144 & -0.0011 & 0.2298 & 0.0523 & 0.2121 & 0.0967 & 0.3275 & 0.0003 \\
\hline Abdominal pain & -0.0766 & -0.1883 & 0.0350 & 0.1783 & 0.0073 & -0.1006 & 0.1151 & 0.8950 \\
\hline Household size & -0.0233 & -0.0384 & -0.0081 & 0.0026 & -0.0091 & -0.0253 & 0.0070 & 0.2662 \\
\hline Mothers with primary education & 0.0120 & -0.1001 & 0.1240 & 0.8344 & -0.0452 & -0.1717 & 0.0813 & 0.4838 \\
\hline Mothers with secondary education & 0.1706 & 0.0033 & 0.3379 & 0.0456 & -0.0270 & -0.2273 & 0.1733 & 0.7914 \\
\hline Fathers with no education & -0.0702 & -0.1837 & 0.0433 & 0.2254 & 0.1205 & -0.0103 & 0.2513 & 0.0710 \\
\hline Fathers with secondary education & 0.1743 & 0.0492 & 0.2995 & 0.0063 & 0.0312 & -0.1144 & 0.1767 & 0.6745 \\
\hline
\end{tabular}

Source: Jimma Longitudinal Family of Youth; Round 2, 2006-2007.

CI: confidence interval.

TABLE 4: Determinants of nutrition status of adolescents in terms of height for age $Z$-scores in Jimma zone, south west Ethiopia, 2011.

\begin{tabular}{|c|c|c|c|c|c|c|c|c|}
\hline \multirow{3}{*}{$\begin{array}{l}\text { Variables } \\
\text { Residence in semiurban }\end{array}$} & \multicolumn{4}{|c|}{ Univariate linear regression } & \multicolumn{4}{|c|}{ Multivariable linear regression } \\
\hline & \multirow{2}{*}{$\frac{\beta}{0.0041}$} & \multicolumn{2}{|c|}{$95 \% \mathrm{CI}$} & \multirow{2}{*}{$\frac{P \text { value }}{0.9417}$} & \multirow{2}{*}{$\frac{\beta}{-0.0487}$} & \multicolumn{2}{|c|}{$95 \% \mathrm{CI}$} & \multirow{2}{*}{$\begin{array}{c}P \text { value } \\
0.4645\end{array}$} \\
\hline & & -0.1065 & 0.1148 & & & -0.1794 & 0.0819 & \\
\hline Residence in rural & -0.2136 & -0.3178 & -0.1093 & 0.0001 & 0.1136 & -0.0495 & 0.2768 & 0.1721 \\
\hline Sex & -0.1473 & -0.2464 & -0.0482 & 0.0036 & -0.1595 & -0.2606 & -0.0585 & 0.0020 \\
\hline Age in years & 0.0638 & 0.0268 & 0.1007 & 0.0007 & -0.0320 & -0.0739 & 0.0100 & 0.1350 \\
\hline Highest grade completed & 0.0917 & 0.0732 & 0.1101 & 0.0000 & 0.1066 & 0.0803 & 0.1328 & 0.0000 \\
\hline Private school & -0.3180 & -0.7355 & 0.0996 & 0.1355 & -0.1189 & -0.5510 & 0.3133 & 0.5897 \\
\hline Community school & -0.8765 & -1.5391 & -0.2140 & 0.0095 & -1.2114 & -1.9757 & -0.4471 & 0.0019 \\
\hline Other type of school & -0.5280 & -1.0622 & 0.0062 & 0.0527 & -0.0004 & -0.5486 & 0.5478 & 0.9988 \\
\hline Household income & 0.0006 & 0.0003 & 0.0008 & 0.0000 & 0.0005 & 0.0002 & 0.0007 & 0.0014 \\
\hline Job & 0.1258 & 0.0159 & 0.2356 & 0.0248 & 0.2198 & 0.1051 & 0.3345 & 0.0002 \\
\hline Abdominal pain & -0.1451 & -0.2514 & -0.0388 & 0.0075 & -0.1328 & -0.2401 & -0.0255 & 0.0153 \\
\hline Household size & -0.0254 & -0.0398 & -0.0110 & 0.0006 & -0.0224 & -0.0384 & -0.0064 & 0.0062 \\
\hline Mothers primary education & -0.0649 & -0.1720 & 0.0422 & 0.2347 & -0.0963 & -0.2222 & 0.0296 & 0.1336 \\
\hline Mothers secondary education & 0.2982 & 0.1389 & 0.4574 & 0.0002 & 0.0747 & -0.1248 & 0.2741 & 0.4628 \\
\hline Fathers no education & -0.0874 & -0.1959 & 0.0211 & 0.1144 & 0.0716 & -0.0585 & 0.2018 & 0.2805 \\
\hline Fathers secondary education & 0.1536 & 0.0337 & 0.2735 & 0.0121 & -0.0804 & -0.2253 & 0.0646 & 0.2770 \\
\hline
\end{tabular}

Source: Jimma Longitudinal Family of Youth; Round 2, 2006-2007.

CI: confidence interval.

Age $z$-score has previously been reported $[5,8]$. The risk of underweight was, on average, significantly higher for younger adolescents than older adolescents.

Studies have suggested a positive association between BMI for Age $z$-score and educational status and employment $[7,8,12,16,17]$. Our study found that highest grade completed was positively associated with BMI for Age $z$-score and Height for Age $z$-score. They indicated that adolescents who receive even a minimal education are generally more aware than those who have no education of how to utilize available resources for the improvement of their own nutritional status and that of their families. Education may enable them to make independent decisions, to be accepted by other household members, and to have greater access to household resources that are important to nutritional status $[16,17]$.

Our study found that job was positively associated with BMI for Age $z$-score and Height for Age $z$-score. The risk of underweight and stunted was significantly high, on average, for unemployed adolescents than employed adolescents in Jimma zone. This finding is consistent with other studies 
[18]. They indicated that unemployment is a significant factor for chronic energy deficiency in these adolescents as compared with employed adolescents. Our study also found that adolescents who attended their last school in community school was positively associated with BMI for Age $z$-score.

Studies have demonstrated the connection between Height for Age $z$-score and household income [6-8]. Our study also indicated that household income was positively associated with Height for Age $z$-score.

We found that male gender was negatively associated with BMI for Age $z$-score and Height for Age $z$-score, as previously reported by others [4]. The risk of underweight was, on average, significantly higher for adolescent males than adolescent females. This may be because of the fact that biological, behavioral, and sociocultural mechanisms have been proposed for the gender differences in morbidity and mortality. Biologically, female subjects have an advantage for better health and longer survival because of the role of sex hormones in modulating lipid levels and increasing immune response. In addition, the difference in morbidity and mortality between boys and girls is further related to individual lifestyle, the use of health care, and health and illness behaviors and practices. For example, adolescent boys are more likely to smoke and have higher propensities of taking greater risks that expose them to injury.

The result also showed that residence in rural was negatively associated with the Height for Age $z$-score which is consistent with reports of studies in Ethiopia and SubSaharan Africa $[8,9,18,19]$. The observed urban-rural difference could be an indication of low access and use of health services in the rural areas as compared with urban areas. In general, people living in cities have better health and lower death rates than rural residents, even though the urban poor often live in unsanitary and crowded conditions. Compared with rural residents, urban residents have better access to medical services and are more easily reached by immunization and educational campaign.

We found also that household size was negatively associated with the Height for Age $z$-score, as previously reported by others $[3,6]$. In addition, abdominal pain and last school attended in community were negatively associated with the Height for Age $z$-score.

We acknowledge a number of limitations in our study. As the study involved adolescents who are at the different stages of academic status, we used the highest grade completed as a measure of educational attainment that can serve across all age groups. However, there are other measures of educational attainment that were not captured. The fact that we did not have data from the school records regarding the academic performances is also a limitation of our analysis.

\section{Conclusion}

In conclusion, the study revealed that age of the adolescents, gender, educational status, employment status, and type of last school attended were associated with underweight; gender, place of residence, household size, household income, educational status, employment status, type of last school attended, and abdominal pain were associated with stunted. Thus, underweight and stunting are the reflection of socioeconomic development demanding combination of different types of policies and programs for its solution. To reduce and prevent underweight and stunting, strategies need to be involved and more targeted interventions. Promoting gender equality through effective behavior change communications needs to be considered. Further research will help to understand and identify the most effective strategies for reducing adolescent malnutrition in the study area.

\section{Abbreviations}

BMI: Body mass index.

\section{Conflict of Interests}

The authors declare that they have no conflict of interests.

\section{Authors' Contribution}

The authors' responsibilities were as follows. Huruy Assefa, Tefera Belachew, and Legesse Negash designed and supervised the study and assisted in the analysis and interpretation of the data. All authors critically reviewed the paper. Huruy Assefa, the corresponding author, did the analysis and drafted the paper and had the responsibility to submit it for publication.

\section{Acknowledgments}

The Jimma Longitudinal Family Survey of Youth was funded by the Packard Foundation, Campton Foundation, the National Institute of Health, and the National Science Foundation. The authors are extremely grateful to research team members and Professor Tefera Belachew.

\section{References}

[1] D. Cordonnier, "Événements quotidiens et bienêtre à l'adolescence. Vers denouvelles stratégies d'éducation pour la santé," Blackwell Scientific Publication, pp. 68-89, 1995.

[2] A. Shahid, F. R. Siddiqui, M. A. Bhatti, M. Ahmed, and M. W. Khan, Assessment of Nutritional Status of Adolescent College Girls at Rawalpindi, HOD Community Medicine, Deptartment of Islamic International Medical College, Rawalpindi, Pakistan, 2010.

[3] A. Doustmohammadian, A. R. Dorostymotlagh, A. Keshavarz, H. Sadrzadehyeganeh, and B. Mohammadpour-Ahrangani, "Socio-demographic factors associated with body mass index of female adolescent students in Semnan city, Iran," Malaysian Journal of Nutrition, vol. 15, no. 1, pp. 27-35, 2009.

[4] R. Elena and O. C. luminiţa, Adolescent Malnutrition from Anthropological Perspective, "Francisc I. Rainer" Institute of Anthropology, 2007.

[5] A. Mulugeta, F. Hagos, B. Stoecker et al., "Nutritional status of adolescent girls from rural communities of Tigray, Northern Ethiopia," Ethiopian Journal of Health Development, vol. 23, no. 1, pp. 5-11, 2009. 
[6] I. Ozguven, B. Ersoy, O. Ali Aykan, and P. Dundar Erbay, "Evaluation of nutritional status in Turkish adolescents as related to gender and socioeconomic status," Journal of Clinical Research in Pediatric Endocrinology, vol. 2, no. 3, pp. 111-116, 2010.

[7] E. Loaiza, Edilberto Maternal Nutritional Status, DHS Comparative Studies no.24, Macro International, Calverton, Md, USA, 1997.

[8] H. Teller and G. Yimar, "Levels and determinants of malnutrition in adolescent and adult women in Southern Ethiopia," Ethiopian Journal of Health Development, vol. 14, no. 1, pp. 5766, 2000.

[9] Y. Mesert, H. Jemal, K. Hailu, and L. Fleming, "Socioeconomic and demographic factors affecting body mass index of adolescents students aged 10-19 in Ambo (a Rural Town) in Ethiopia," International Journal of Biomedical Science, vol. 6, no. 4, pp. 321326, 2010.

[10] J. Haidar, D. HaileMariam, T. Dee, and H. Kloos, "Food, diet and nutrition," in The Epidemiology and Ecology of Health and Disease in Ethiopia, Y. Berhane, D. Haile Mariam, and H. Kloos, Eds., pp. 90-109, Shama Books, Addis Ababa, Ethiopia, 2006.

[11] A. Zeleke, Prevalence and Determinants of Childhood and Adolescent Overweight and Obesity among Primary School Students in Addis Ababa, vol. 90, School of Public Health, Addis Ababa University, 2007.

[12] S. Chaturvedi, U. Kapil, N. Gnanasekaran, H. P. S. Sachdev, R. M. Pandey, and T. Bhanti, "Nutrient intake amongst adolescent girls belonging to poor socioeconomic group of rural area of Rajasthan," Indian Pediatrics, vol. 33, no. 3, pp. 197-201, 1996.

[13] T. J. Cole, "Weight-stature indices to measure underweight, overweight and obesity," in Anthropometric Assessment of Nutritional Status, J. H. Himes, Ed., pp. 83-111, 1991.

[14] L. Kish, "A procedure for objective respondent selection within the household," Journal of the American Statistical Association, pp. 380-387, 1949.

[15] WHO, AnthroPlus for Personal Computers Manual: Software for Assessing Growth of the World's Children and adolescents, World Health Organization, Geneva, Switzerland, 2009.

[16] Second Report on the World Nutrition Situation-Volume I: Global and Regional Results, Administration Committee on Coordination-Sub-Committee on Nutrition (ACC/SCN), New York, NY, USA, 1992.

[17] Second Report on the World Nutrition Situation-Volume II: Country Trends Methods and Statistics, Administration Committee on Coordination-Sub-Committee on Nutrition (ACC/SCN), New York, NY, USA, 1992.

[18] G. Woldemariam and T. Genebo, Determinants of Nutritional Status of Women and Children in Ethiopia, Ethiopia Health and Nutrition Research Institute, Addis Ababa, Ethiopia; ORC Macro, Calverton, Md, USA, 2002.

[19] T. Zerihun, C. P. Larson, and J. A. Hanley, "Anthropometric status of Oromo women of child bearing age in rural southwestern Ethiopia," Ethiopian Journal of Health Development, vol. 11, no. 3, pp. 1-7, 1997. 


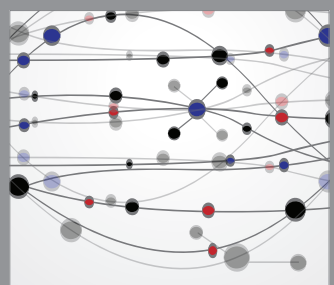

The Scientific World Journal
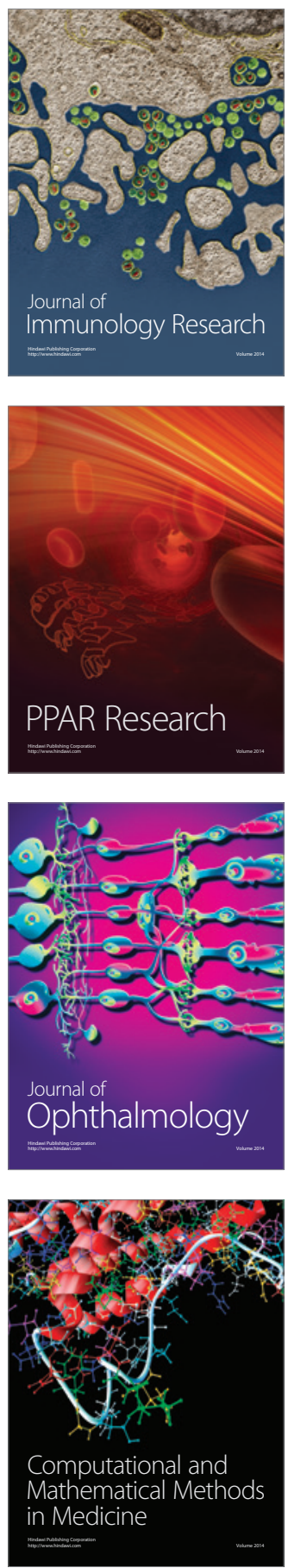

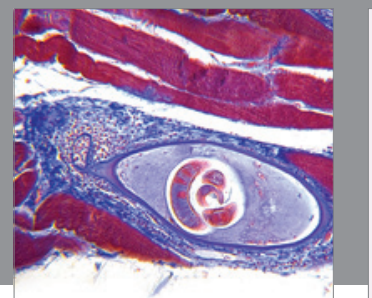

Gastroenterology

Research and Practice
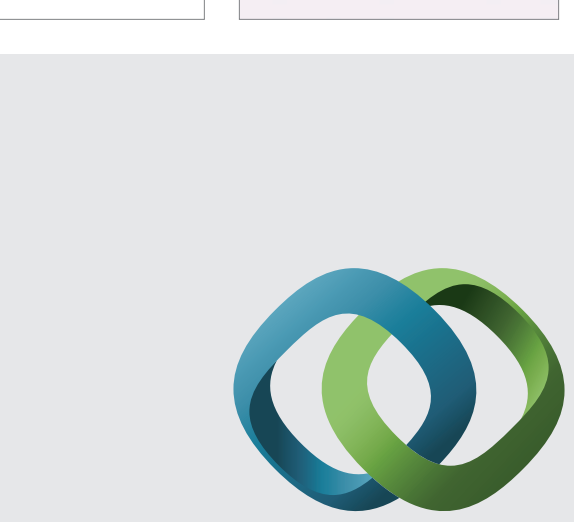

\section{Hindawi}

Submit your manuscripts at

http://www.hindawi.com
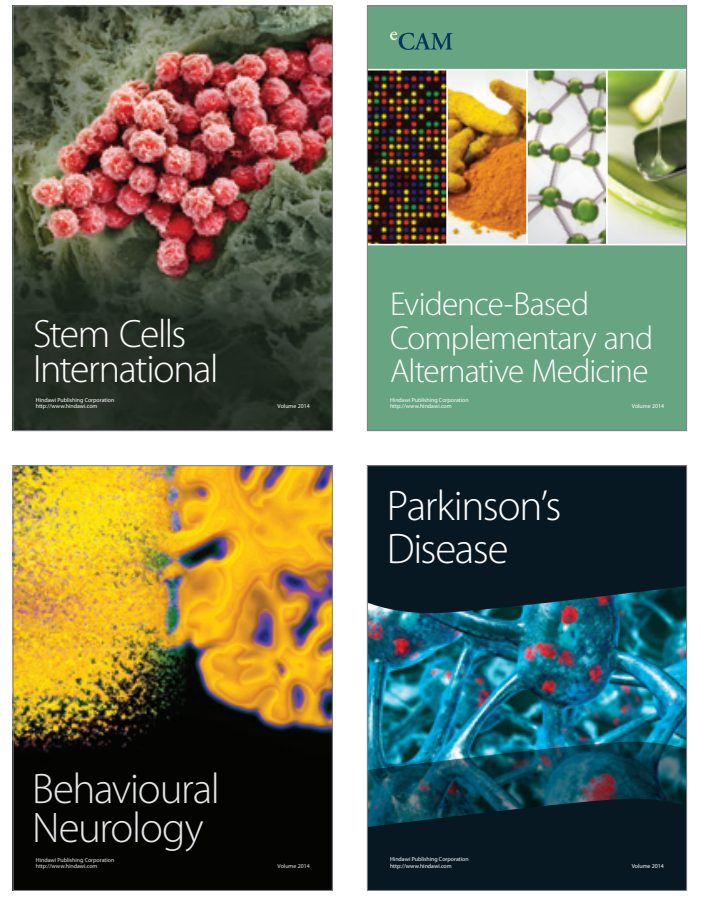
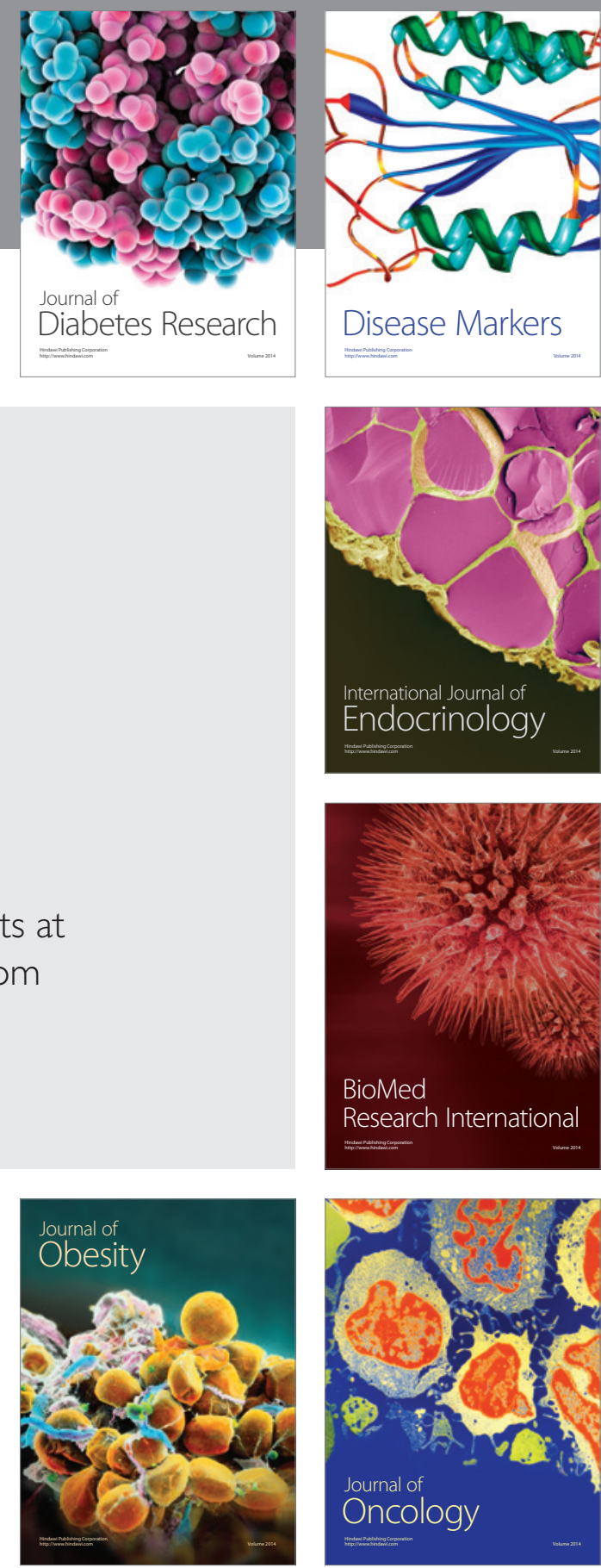

Disease Markers
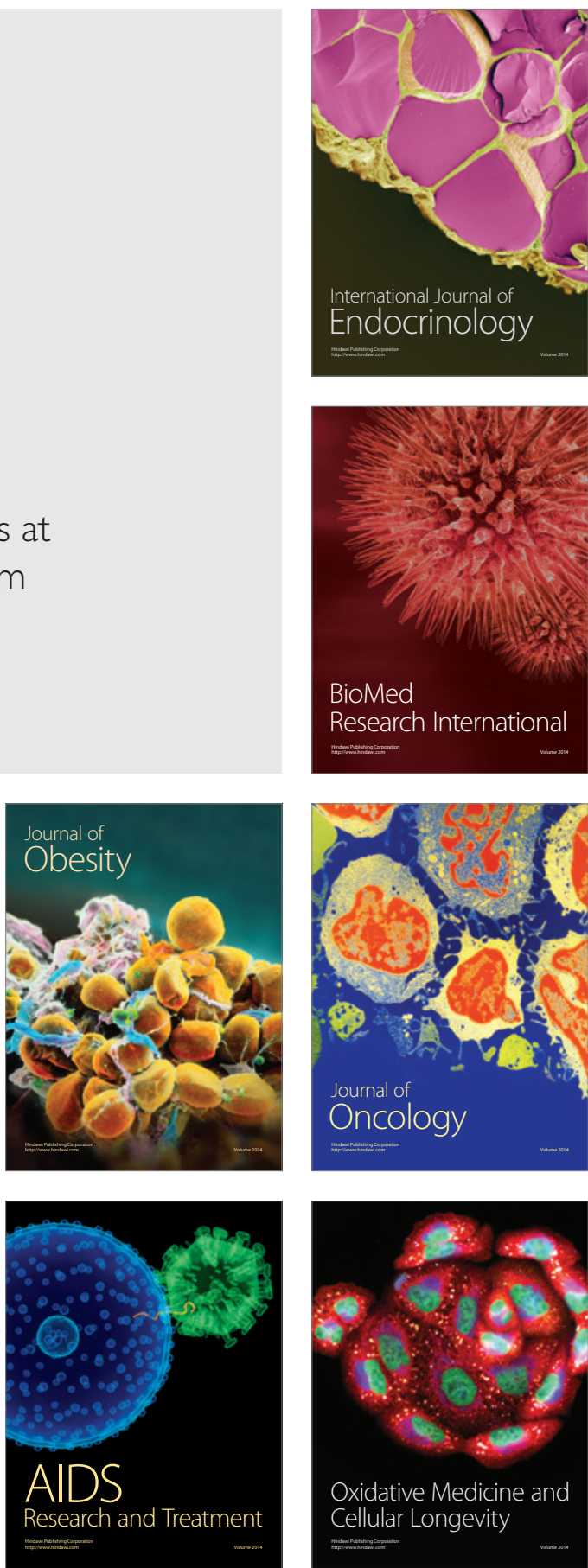